\title{
The Development to Control Simultaneously Viscosity and Separation Temperature of a Two Phase Lubricant for Practical Use
}

\author{
Kumiko Kamata, Yasushi Kawamura, Ryuji Maruyama, Eiji Nagatomi* and Hiroyuki Tazaki \\ Central Research and Development Laboratory, Showa Shell Sekiyu K.K. \\ 4052-2 Nakatsu, Aikawa-cho, Aikoh-gun, Kanagawa 243-0303, JAPAN \\ *Corresponding author: Eiji.E.Nagatomi@showa-shell.co.jp
}

( Manuscript received 14 June 2015; accepted 07 January 2016; published 31 January 2016 )

\begin{abstract}
Fuel economy is a major challenge for the automotive industry. A key way to improve lubricant fuel efficiency is by using polymers as viscosity index improvers to maximise the viscosity index of the lubricants. The viscosity index of automotive lubricants has an upper limit of around 250 because usage of high treat rates can lead to shear stability and flash point issues. To overcome this, the concept of two phase lubricants was reported in former literature but the practical application had not been examined. In this paper, the practical application with an additional ability to control viscosity and separation temperature simultaneously of a two phase lubricant is reported. It is possible to formulate a two phase lubricant with mineral or synthetic base oil and polyalkylene glycol to achieve viscosity index of 500 and keeping the properties of shear stability and flash point on a competitive level as of commercial single phase lubricants. Also, there is little evidence of issues with the lubrication properties. It was shown that additions of Di-isononyl adipate acting as a control element simultaneously control the viscosity and separating temperature of the two phase lubricants.
\end{abstract}

Keywords: lubricant, polyalkylene glycol, high viscosity index, fuel economy, homogenous, heterogeneous

\section{Introduction}

Fuel economy to reduce carbon dioxygen emission from vehicles is a major challenge for the automotive industry in recent years [1,2]. Viscosities of the lubricants below room temperature have recently been lowered to reduce energy losses [3-5], and a key way to improve lubricant fuel efficiency of vehicles is by using polymers as viscosity index improvers with thinner base oils $[3,6]$. The viscosity index of automotive lubricants has an upper limit of around 250 which is a consequence of shear stability and flash point properties of this high viscosity index based lubricants.

To overcome this, the concept of two phase lubricants was reported in former literature but the practical application had not been examined [7]. The two phase lubricants consist of the low and high viscosity base oil which are miscible at high temperature but not at lower temperature. To expand the applicability of this concept for lubricants, we have investigated the viscosity properties and evaluated other properties including tribological properties of the two phase lubricants those possess a high viscosity index of more than 500 [8-11]. During the investigations, we have found that the two phase lubricants reported in the literature had little flexibilities to control the viscosity properties at different temperatures. In this paper, the practical application of such technology, with additional ability to control viscosity and separation temperature of a two phase lubricant is reported.

\section{The concept of two phase lubricant}

A two phase lubricant consists of low and high viscosity components [7]. Supposing the practical use, commercially available compounds are used for these components, and mineral base oils or poly- $\alpha$-olefins are used for the low viscosity components. The low and the high viscosity components need to be separated because of the different polarities and densities at around room temperature. Polyalkylene glycols, those are used as base oils for worm gear oils, are chosen for the high viscosity component which delivers a higher polarity and density than mineral base oils or poly- $\alpha$-olefins. The polyalkylene glycols are co-polymerising compounds of alkylene oxide, and contain oxygen atoms in their molecules (Fig. 1). These polyalkylene glycols are<smiles>CCCOC(C)(C)C(C)(C)CC(C)O</smiles>

Fig. 1 Structure of Poly alkylene glycols (Ex. Poly ethylene propylene glycols) 
separated in two phase lubricants below room temperature, but they begin to dissolve in the low viscosity component at higher temperature.

Figure 2 shows a schematic drawing of a gear box where a two phase lubricant is used. The upper figure shows the appearance at higher temperature, i.e. Fig. 2(a) is at the highest temperature, and Fig. 2(c) is at the lowest temperature. The two phases are separated at low temperature (Fig. 2(c)) and the low viscosity component presents as the upper phase and the high viscosity component presents as the lower phase. The gears are lubricated with only the low viscosity component at low

(a)

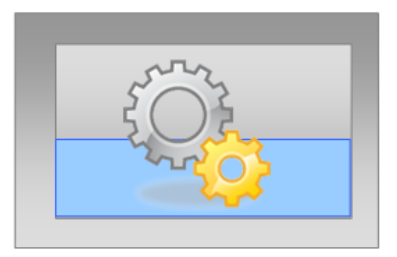

(b)

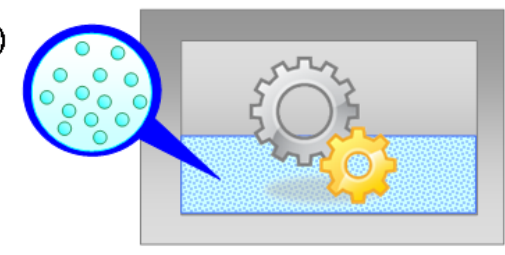

(c)

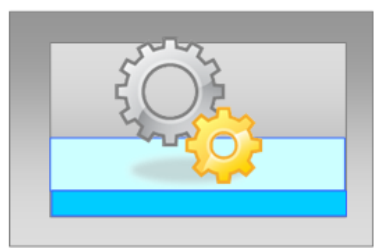

Fig. 2 Images of two phase lubricant (a) at high temperature (homogeneous condition) (b) around separation temperature (c) at low temperature (separated condition) temperatures to reduce agitation resistance of rotating gears. As the oil temperature increases, the high viscosity component becomes miscible with the low viscosity component (Fig. 2(b)) and viscosity of the now combined lubricating phase increases (Fig. 2 (a)). This phenomenon is reversible as the temperature drops. As the two phase lubricants show low viscosity at lower temperature and high viscosity at higher temperature, the apparent viscosity index is expected to be very high. The temperature at which the high viscosity component is dissolved in the low viscosity component is referred to as the separation temperature. Therefore we can see the steps from Fig. 2(a) to Fig. 2(c) as migration from a homogenous status to a heterogeneous status which makes this concept so unique.

\section{Experimental methods}

3.1. Base oil components used for two phase lubricants

Table 1 shows base oil components used for two phase lubricants. Mineral oil or poly- $\alpha$-olefin was used as the low viscosity component and a polyalkylene glycol as the high viscosity component. Diisononyl adipate was used as the control element, which will be discussed later in section 4.3. The additive package used was the same one as one which is commercially used in an automatic transmission fluid (ATF) - which acts as the reference fluid in this paper. The formulations of two phase lubricant $\mathrm{A}$ and the commercial ATF are shown in Table 2

3.2. Determination of separation temperature of two phase lubricants

The components of the two phase lubricant were mixed with a magnetic stirrer at $100^{\circ} \mathrm{C}$, and the lubricant was confirmed in the homogeneous condition by visual inspection. Then, the lubricant was cooled

Table 1 Base oil components used for two phase lubricants

\begin{tabular}{lcc}
\hline Base oil component & Kinematic viscosity at $100^{\circ} \mathrm{C} / \mathrm{mm}^{2} \mathrm{~s}^{-1}$ & Density at $20^{\circ} \mathrm{C} / \mathrm{g} \mathrm{cm}^{-3}$ \\
\hline Mineral oil A & 2.3 & 0.820 \\
Poly- $\alpha$-olefin & 3.9 & 0.819 \\
Polyalkylene glycol A & 93.0 & 1.003 \\
Polyalkylene glycol B & 22.6 & 1.000 \\
Di-isononyl adipate & 3.0 & 0.924 \\
\hline
\end{tabular}

Table 2 Formulation of two phase lubricant A and the commercial ATF

\begin{tabular}{lcc}
\hline & Two phase lubricant A & Commercial ATF \\
\hline Mineral oil A / mass\% & 75.0 & - \\
Mineral oil B / mass\% & - & 86.0 \\
Polyalkylene glycol A / mass\% $\%$ & 15.8 & - \\
Poly alkyl methacrylate / mass\% & - & 4.8 \\
ATF additive package A / mass\% & 9.0 & 9.0 \\
Pour point dispersant / mass\% & 0.2 & 0.2 \\
\hline Separation temperature ${ }^{\# /} /{ }^{\circ} \mathrm{C}$ & 78 & - \\
Separation temperature $^{\$)} /{ }^{\circ} \mathrm{C}$ & 77.9 & - \\
\hline
\end{tabular}

\#) Measured by visual inspection \$) Measured by utilising the method and the apparatus of the aniline point measurement 
down to room temperature. After it becomes suspended and finally separated, it was heated to $100^{\circ} \mathrm{C}$ with stirring again. The separation temperature was at the temperature of the beginning of the suspension by visual inspection during the cooling down stage without stirring.

The separation temperature was also determined by the aniline point measurement with AAP-6 apparatus from Tanaka Kagaku [12]. The components of the two phase lubricant were mixed with a magnetic stirrer at $100^{\circ} \mathrm{C}$, and the homogenisation of the lubricant in the fluid was confirmed by visual inspection. Then, the lubricant was put into the test tube of the aniline point apparatus, and cooled down to $3^{\circ} \mathrm{C}$ above the expected separation temperature of the two phase lubricant. Light beam was introduced to the lubricant which was detected then by a sensor. The intensity of the light from the test tube was adjusted to $40 \%$ of that of the initial irradiation. While lubricant temperature was dropped at the rate of $0.5-1.0^{\circ} \mathrm{C} / \mathrm{min}$, the change of the intensity was recorded. The separation temperature was defined when the intensity permanently dropped below the initial value. The measurement was carried out three times, and the average was reported as the separation temperature of the two phase lubricant. Figure 3 shows the example of the measurement. In this given case, the separation temperature was $77.9^{\circ} \mathrm{C}$.

3.3. Viscosity measurement by the oscillation viscometer

Viscosity properties of the test fluids were measured by the oscillation viscometer, SV-10 Vibro-viscometer from A \& D Co. Ltd., and by the Ubbelohde viscometer. This section describes the viscosity measurement method for the two phase lubricants by the oscillation viscometer in accordance with JIS Z8803 [13].

The oscillation viscometer can continuously measure viscosity of fluids with changing temperature, and the unit of measurement values is $\mathrm{mPa} \mathrm{s} \mathrm{g} \mathrm{cm}^{-3}$. This value is a result of multiplying dynamic viscosity and density of the fluid. The viscosity of the upper phase of the two

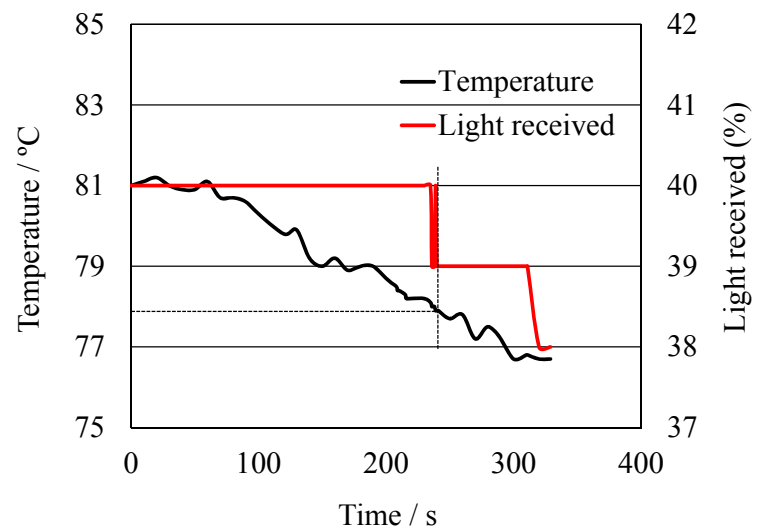

Fig. 3 Separation temperature measurement result of two phase lubricant A by utilising the method and the apparatus of the aniline point measurement

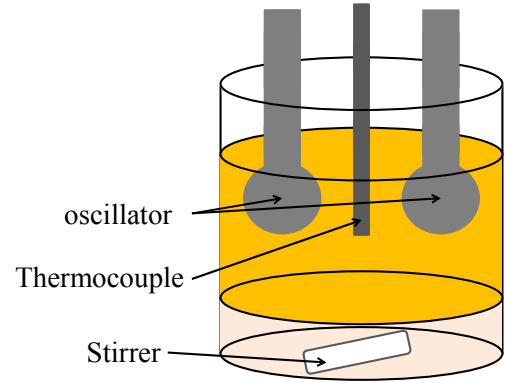

Fig. 4 The oscillation viscometer

phase lubricants was measured by the viscometer to set the oscillator in the upper phase as shown in Fig. 4 when the two phases were completely separated. The lubricants were heated while stirring until the temperature of it reached $100^{\circ} \mathrm{C}$, and then, the viscosity of the lubricants was measured by the oscillation viscometer cooled down by room temperature to $30^{\circ} \mathrm{C}$ without stirring. In some cases, the viscosity of the lubricants was measured with stirring at $500 \mathrm{rpm}$.

\subsection{Oil film thickness measurements}

Oil film thickness of the fluids was measured by white light optical interferometry using EHD2 Ultra Thin Film Measurement System from PCS instruments. The measurement procedure was the same as that in the reported paper by Nakano and Spikes [14].

A circular EHD contact was obtained by applying a constant load between a $10 \mathrm{~mm}$ thick glass disk and a $25.4 \mathrm{~mm}$ diameter bearing steel ball. The glass disk surface in contact with the ball was coated with thin semi-reflecting layer of chromium, on top which was a spacer layer of silica approximately $500 \mathrm{~nm}$ thick. White light was shone into the contact, and some was reflected from the chromium layer, while some passed through the spacer layer and any oil film present, to be reflected from the steel ball. The two beams recombined and interfered. The interfered light from a strip across the contact was then passed into spectrometer, where it was dispersed and detected by a CCD camera. A frame grabber captured this image at a preselected angular position of the rotating disk and a computer program determined the wavelength of maximum constructive interference in the central region of the contact. The oil film thickness was then calculated from the difference between the measured film thickness and the thickness of the silica spacer layer at the identical angular position of the disk.

\subsection{Other test methods}

Other test methods used to analyse items such as elements and to measure general properties and practical performances of the commercial ATF and the two phase lubricants are listed in Table 3.

The general properties and practical performance test measurements at the temperature above the separation temperature of the two phase lubricant were carried out under homogeneous condition of the 
Table 3 Test methods used for element analyses, general properties and practical performance tests of test fluids

\begin{tabular}{lc}
\hline & Test method \\
\hline Element analyses & \\
Sulfur & JPI 5S-38-03 \\
Nitrogen & JIS K 2609:1998 \\
Other additive elements & JPI 5S-38-03 \\
& \\
General properties & \\
Kinematic viscosity & ASTM D445 \\
Density & ASTM D4052 \\
Brookfield viscosity & ASTM D2983 \\
Flash point & ASTM D92 \\
Aniline point & ASTM D611 \\
Foaming characteristics & ASTM D892 \\
Acid number & JIS K 2501:2003 \\
Base number (HCl method) & JIS K 2501:2003 \\
& \\
Practical performance tests & \\
Shell 4-ball EP test & ASTM D2783 \\
Shell 4-ball Wear test & ASTM D4172 \\
Indiana stirring oxidation test (ISOT) & JIS K 2514-1:2013 \\
Sonic share stability test & ASTM D2603 \\
Bearing fatigue test & IP305/74 \\
\hline
\end{tabular}

lubricant. The components of the two phase lubricant were mixed with a magnetic stirrer at $100^{\circ} \mathrm{C}$, and the lubricant was confirmed to be homogeneous by visual inspection. Then, the lubricant was put into the test apparatus to run the test in accordance with the method showed in Table 3. Some of the tests were conducted under heterogeneous conditions at lower temperatures. Therefor components of the two phase lubricant were directly put into the test apparatus to run the test in accordance with the method showed in Table 3.

\section{Results and discussion}

4.1. Viscosity and viscosity index of the two phase lubricants

Figure 5 shows the viscosities of two phase lubricant $\mathrm{A}$ and the commercial ATF from $30^{\circ} \mathrm{C}$ to $100^{\circ} \mathrm{C}$ measured by the oscillation viscometer with and without stirring. The separation temperature of two phase lubricant A was $78^{\circ} \mathrm{C}$ (Table 2).

\subsubsection{Viscosity measurement without stirring}

Under $78^{\circ} \mathrm{C}$, temperature under the separation temperature of two phase lubricant $\mathrm{A}$, the high and low viscosity components are separated without stirring. The viscosity measured below $78^{\circ} \mathrm{C}$ (Fig. 5(b)) was much lower compared to the commercial ATF (Fig. 5(a)). Above $78^{\circ} \mathrm{C}$, meaning above the separation temperature, polyalkylene glycol dissolved in the mineral oil, and the lubricant becomes homogeneous. As the result, the two phase lubricant A showed the similar viscosity curve to the commercial ATF.

Viscosity index of the two phase lubricants was

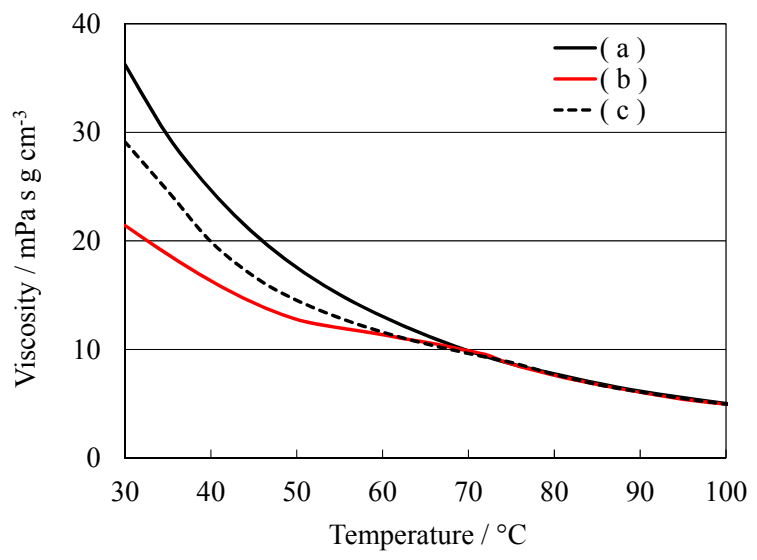

Fig. 5 Viscosities of (a) the commercial ATF, (b) two phase lubricant A under still condition and (c) two phase lubricant A under stirring condition measured by the oscillation viscometer

calculated from the kinematic viscosity at $40^{\circ} \mathrm{C}$ of the upper phase, which was separated by using separating funnel, of the two phase lubricants and that at $100^{\circ} \mathrm{C}$ of homogeneous condition of the two phase lubricants (Table 4). It is called "apparent" viscosity index in this paper. The kinematic viscosity at $40^{\circ} \mathrm{C}$ of the mineral oil which is the low viscosity component of two phase lubricant A was $15.1 \mathrm{~mm}^{2} \mathrm{~s}^{-1}$, and it was much lower than the kinematic viscosity at $40^{\circ} \mathrm{C}$ of the commercial ATF. The kinematic viscosities at $100^{\circ} \mathrm{C}$ of both - two phase lubricant A and the commercial ATF - were $6.9 \mathrm{~mm}^{2} \mathrm{~s}^{-1}$. As a result, the "apparent" viscosity index of two phase 
Table 4 Kinematic viscosity and viscosity index of two phase lubricant A and the commercial ATF

\begin{tabular}{lccc}
\hline & \multicolumn{2}{c}{ Two phase lubricant A } & Commercial ATF \\
\cline { 2 - 4 } & Upper phase & $\begin{array}{c}\text { Homogeneous } \\
\text { condition }\end{array}$ & Con \\
\hline Kinematic viscosity at $40^{\circ} \mathrm{C} / \mathrm{mm}^{2} \mathrm{~s}^{-1}$ & 15.1 & - & 33.0 \\
Kinematic viscosity at $100^{\circ} \mathrm{C} / \mathrm{mm}^{2} \mathrm{~s}^{-1}$ & - & $508^{\#}$ & 6.94 \\
\hline Viscosity index & \multicolumn{2}{c}{176} \\
\hline \#) Calculated from the kinematic viscosity at $40^{\circ} \mathrm{C}$ of upper phase of two phase lubricant A and that at \\
$100^{\circ} \mathrm{C}$ of two phase lubricant A
\end{tabular}

lubricant A was calculated as 508. It is difficult to show such a high viscosity index for the current commercial lubricants with mineral or synthetic base oils with polymers used as viscosity index improvers. This suggests that the two phase lubricant technologies are effective for designing high viscosity index lubricants and for developing fuel efficient ones which can reduce agitation resistance at low temperature and maintain moderate viscosity at high temperature.

\subsubsection{Viscosity measurement with stirring}

Below $78^{\circ} \mathrm{C}$, the high and low viscosity components are heterogeneously mixed, and the lubricant is suspended with stirring. The viscosity of the suspended two phase lubricant A showed higher values (Fig. 5(c)) than that of two phase lubricant A under still condition (Fig. 5(b)), but still lower than those of the commercial ATF (Fig. 5(a)). Above $78^{\circ} \mathrm{C}$, polyalkylene glycol dissolved in the mineral oil, and two phase lubricant $\mathrm{A}$ showed the similar viscosity curve to the commercial ATF.

It was difficult for the two phase lubricants to measure precise kinematic viscosity at under the separation temperature, because the fluids are suspended. For this reason, the viscosity index cannot be calculated. But, the above results clearly indicated that the two phase lubricants have higher viscosity index than the commercial ATF under stirring condition. This means that the two phase lubricant technologies have also advantage for designing the fuel economy lubricants.

\subsection{Practical performances of two phase lubricants}

The results of the element analyses of the fluids are shown in Table 5. As shown in Table 2, both two phase lubricant A and the commercial ATF contained the same amount of the same additive package and pour point dispersant. Tables (6-9) show the other general properties: tribological properties, oxidation stability and share stability of two phase lubricant $A$ in comparison with the commercial ATF. Two phase lubricant A showed lower viscosity at $-40^{\circ} \mathrm{C}$ and lower flash point than the commercial ATF (Table 6). These properties are a trade-off of high viscosity index for conventional lubricants which are formulated with low viscosity mineral base oil and a viscosity index improver [3]. The two phase lubricant technology does not use these combinations, which is resulting in a better performance on low temperature viscosity and flash point. Other properties, such as foaming, EP, anti-wear properties and oxidation stabilities, of two phase lubricant A showed in Tables (6-8) were competitive with those of the commercial ATF, indicating that the two phase lubricant technology could be applied to current available commercial fluids such as ATF's.

Figure 6 describes the oil film thickness measurement results of two phase lubricant $\mathrm{A}$ and the commercial ATF under $0.53 \mathrm{GPa}$ at $90^{\circ} \mathrm{C}$, and Fig. 7 shows the bearing fatigue life test results of both fluids with $3.34 \mathrm{kN}$ load, $1500 \mathrm{rpm}$ at $90^{\circ} \mathrm{C}$. Two phase lubricant A showed better bearing fatigue life than the commercial ATF (Fig. 7), although these two fluids showed the similar oil film thickness (Fig. 6). It is known that there are correlation between the oil film thickness and the fatigue life of the lubricants when the same additive formulations are used $[15,16]$. Two phase lubricant A do not contain any viscosity improvers, which cause a viscosity decrease under severe shear condition in the fatigue test, and this difference in formulation could be the main reason of the extended fatigue life of two phase lubricant $\mathrm{A}$. The kinematic

Table 5 Results of element analyses of two phase lubricant A and the commercial ATF

\begin{tabular}{lcccc}
\hline \multirow{2}{*}{ Elements } & \multicolumn{3}{c}{ Two phase lubricant A } & Commercial ATF \\
\cline { 2 - 4 } & $\begin{array}{c}\text { Homogeneous } \\
\text { condition }\end{array}$ & Upper phase & Lower phase & 0.15 \\
\hline Sulfur / mass\% & 0.11 & 0.10 & 0.14 & 0.20 \\
Nitrogen / mass\% & 0.18 & 0.12 & & \\
& & & 0.001 & 0.023 \\
Phosphorous / mass\% & 0.023 & 0.027 & 0.000 & 0.012 \\
Calcium / mass\% & 0.012 & 0.015 & 0.003 & 0.007 \\
Boron / mass\% & 0.007 & 0.007 & & 0.15 \\
\hline
\end{tabular}


Table 6 Other general properties of two phase lubricant A and the commercial ATF

\begin{tabular}{lcc}
\hline & Two phase lubricant A & Commercial ATF \\
\hline Brookfield viscosity at $-40^{\circ} \mathrm{C} / \mathrm{mPa} \mathrm{s}$ & $3600^{\#}$ & 16400 \\
Flash point $/{ }^{\circ} \mathrm{C}$ & $202^{\$}$ & 224 \\
Aniline point $/{ }^{\circ} \mathrm{C}$ & $116^{\$}$ & 111 \\
Foaming characteristics $/ \mathrm{ml}$ & & \\
Sequence I $\left(\right.$ at $\left.24^{\circ} \mathrm{C}\right)$ & $0^{\&}$ & 0 \\
Sequence II $\left(\right.$ at $\left.93.5^{\circ} \mathrm{C}\right)$ & $50^{\$}$ & 30 \\
Sequence III $\left(\right.$ at $\left.24^{\circ} \mathrm{C}\right)$ & $20^{\&}$ & 0 \\
\hline
\end{tabular}

\#) Measured under heterogeneous condition mixed with rotation of measurement spindle

\$) Measured under homogeneous condition

\&) Measured under heterogeneous condition mixing with bubbles from diffuser stone

Table 7 Tribological properties of the two phase lubricant A under homogeneous condition and the commercial ATF

\begin{tabular}{cccc}
\hline & Test condition & Two phase lubricant A & Commercial ATF \\
\hline Shell 4-ball EP test & $1800 \mathrm{rpm}, 90^{\circ} \mathrm{C}$ & & \\
LNL & & $63 \mathrm{~N}$ & $63 \mathrm{~N}$ \\
WL & & $200 \mathrm{~N}$ & $200 \mathrm{~N}$ \\
Shell 4-ball Wear test & $1800 \mathrm{rpm}, 90^{\circ} \mathrm{C}$, & $0.45 \mathrm{~mm}$ & $0.42 \mathrm{~mm}$ \\
\hline
\end{tabular}

Table 8 Oxidation stability test results from ISOT for 192 hours at $150^{\circ} \mathrm{C}$ of two phase lubricant A under homogeneous condition and the commercial ATF

\begin{tabular}{ccc}
\hline & Two phase lubricant A & Commercial ATF \\
\hline Kinematic viscosity at $100^{\circ} \mathrm{C} / \mathrm{mm}^{2} \mathrm{~s}^{-1}$ & 6.90 & 6.94 \\
Before the test & 7.10 & 7.16 \\
After the test & & \\
Acid number / mgKOH g-1 & 1.14 & 1.09 \\
Before the test & 1.09 & 1.09 \\
After the test & & 1.93 \\
Base number / mgKOH g-1 & 1.83 & 0.07 \\
Before the test & 0.12 & \\
After the test & & \\
\hline
\end{tabular}

Table 9 Sonic share stability test results of two phase lubricant A under heterogeneous condition without stirring and the commercial ATF

\begin{tabular}{ccc}
\hline & Two phase lubricant A & Commercial ATF \\
\hline Kinematic viscosity at $100^{\circ} \mathrm{C} / \mathrm{mm}^{2} \mathrm{~s}^{-1}$ & & \\
Before the test & 6.90 & 6.94 \\
After the test & 6.89 & 6.14 \\
Kinematic viscosity change $/ \%$ & 0.2 & 11.9 \\
\hline
\end{tabular}

viscosity change after sonic shear stability test is shown in Table 9, also support this fact. Two phase lubricant A showed superior shear stability in comparison with the commercial ATF.

It should be noted that the above mentioned tribological performance tests were carried out at above the separation temperature, i.e. above $78^{\circ} \mathrm{C}$, indicating that the two phase lubricant was in the homogeneous condition. Table 5 shows that the concentration of some of the elements in the upper phase and the lower phase of two phase lubricant A are different. Because of the polarities of the two phases are different, solubility of each additive in each phase should be different. Analytic data shows that the components containing Phosphorus and Calcium showed little solubility in the lower phase, indicating that anti-wear additive and detergent are missing in the lower phase below separation temperature of the two phase lubricant. There are possibilities for the two phase lubricants to have deteriorated tribological performance when the lubrication was only done by the lower phase at under the separation temperature. However, the lower phase possessed higher polarity and a much higher viscosity than the two phase lubricant at mixing condition at the 


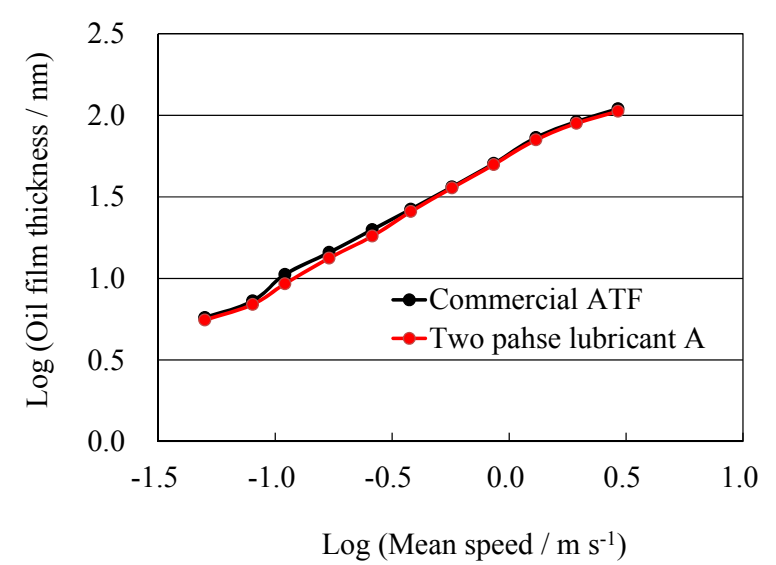

Fig. 6 Oil film thickness measurement results of two phase lubricant A under homogeneous condition and the commercial ATF under $0.53 \mathrm{GPa}$ at $90^{\circ} \mathrm{C}$

same temperature. This led to the suggestion that the lower phase itself could have higher lubricity even some of the additive components are missing.

\subsection{Controlling the separation temperature and viscosity} simultaneously using a polar component

As discussed in Section 2, the higher viscosity component is separated from the two phase lubricant below the separation temperature. To apply the concept in the ideal condition as shown in Fig. 2, controlling the separation temperature is very important. The separation temperature could be determined by the following two parameters.

1) Polarity difference of the low and high viscosity components.

2) Content ratio of the low and high viscosity components.

Densities of the high and low viscosity components are thought to be important parameters to determine the separation temperature. Correlations between the density of polyalkylene glycols and the separation

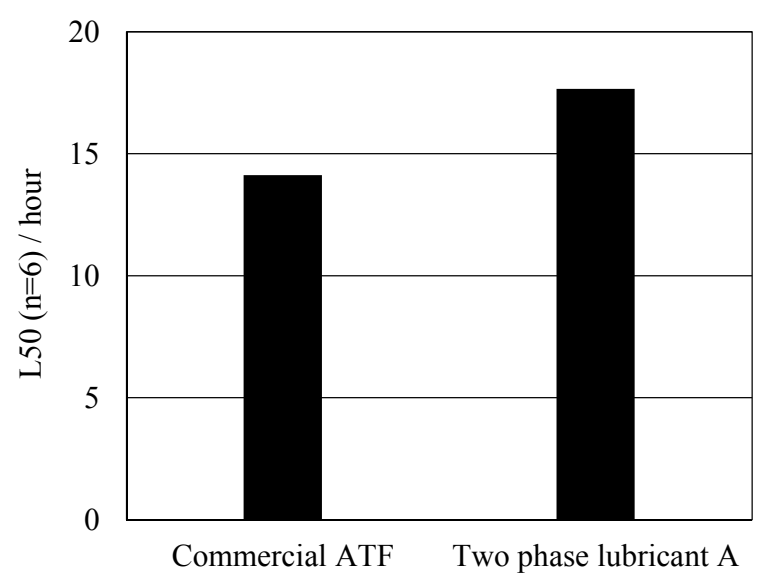

Fig. 7 Ball bearing fatigue life test results of two phase lubricant A under homogeneous condition and the commercial ATF with $3.34 \mathrm{kN}$ load, $1500 \mathrm{rpm}$ at $90^{\circ} \mathrm{C}$

temperature of the two phase lubricants were investigated. Polyalkylene glycols those have different densities were blended with the mineral oil A or poly- $\alpha$-olefin together with ATF additive package B as shown in Table 10. The element analysis results of two phase lubricant B1 are also shown in the same table.

Figure 8 shows the separation temperatures of two phase lubricant B1 and B2. As the density of used polyalkylene glycol increases, the separation temperature increases when the mineral oil or poly- $\alpha$-olefin was used for the low viscosity component as well. Polyalkylene glycols contain both oxygen and carbon atoms in their molecules. The density of the polyalkylene glycols is higher when the oxygen atom content in their molecule is higher, because an oxygen atom is heavier than a carbon atom. When the oxygen content is higher, the polarity of the compounds becomes higher. This means that the density of the polyalkylene glycols should be one of the characteristic parameters of the polarity of them, and that the ratio of

Table $10 \quad$ Formulations and results of element analyses of two phase lubricants with control element

\begin{tabular}{lcc}
\hline & \multicolumn{2}{c}{ Two phase lubricants } \\
\cline { 2 - 3 } & B1 & B2 \\
\hline Components & 70.0 & - \\
Mineral oil A / mass\% & - & 70.0 \\
Poly- $\alpha$-olefin / mass\% & 20.0 & 20.0 \\
Polyalkylene glycols $\$$ / mass\% & 10.0 & 10.0 \\
ATF additive package B / mass\% & & \\
& & - \\
Elements & 0.11 & - \\
Sulfur / mass\% & 0.14 & - \\
Nitrogen / mass\% & & - \\
Phosphorous / mass\% & 0.039 & - \\
Calcium / mass\% & 0.038 & - \\
Boron / mass\% & 0.016 & \\
\hline
\end{tabular}

\$) Polyalkylene glycols those have different densities were used 


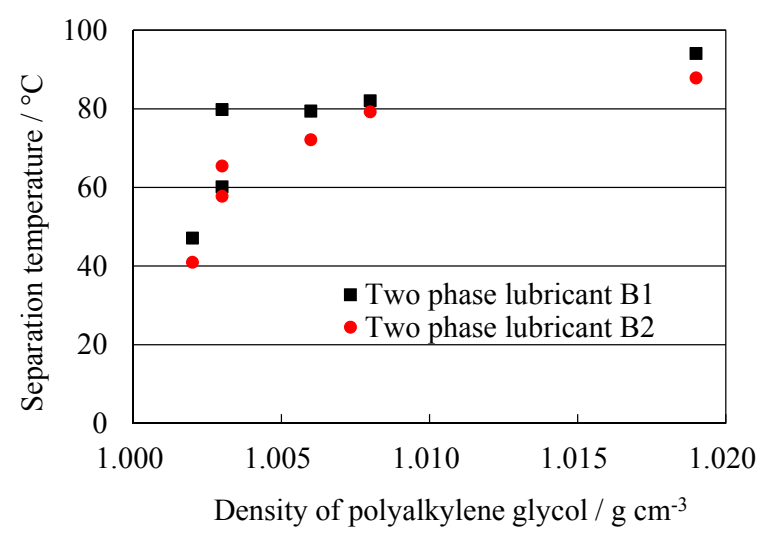

Fig. 8 Correlation between density of polyalkylene glycols and separation temperature of two phase lubricant B1 and B2

oxygen atom to carbon atom in the high viscosity component is related to the separation temperature of the two phase lubricants [11].

The previously reported two phase lubricant system composed of poly- $\alpha$-olefin and polyalkylene glycol representing the two phases. Formulations of these fluids are shown in Table 11 [7]. Figure 9 shows the relation between the separation temperatures and the kinematic viscosity at $100^{\circ} \mathrm{C}$ of the two phase lubricants $\mathrm{C}$ reported in the paper. They showed that the separation temperatures were varied from $25^{\circ} \mathrm{C}$ to $95^{\circ} \mathrm{C}$, and the kinematic viscosity at $100^{\circ} \mathrm{C}$ varies from $4.65 \mathrm{~mm}^{2} \mathrm{~s}^{-1}$ to $18.96 \mathrm{~mm}^{2} \mathrm{~s}^{-1}$ (Table 11 and Fig. 9). The separation temperature increases with higher ratio of the high viscosity component to the low viscosity component. However there is a turnover point at $50 \%$ ratio. Thus, to formulate a lubricant against rigid viscosity specification requirements was difficult, because the separation temperature of the phases varies with increased treat rate of the high viscosity component while the kinematic viscosity also varies greatly at the same time. These viscosity properties of the two phase lubricants in the previous paper are a challenge for practical application.

To overcome the problems as mentioned above, the

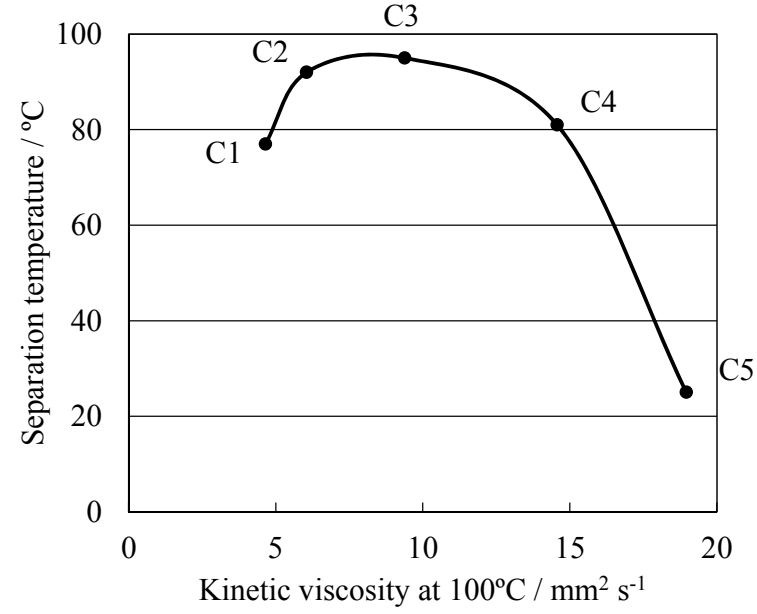

Fig. 9 Separation temperature and kinematic viscosity at $100^{\circ} \mathrm{C}$ of conventional two phase lubricants $\mathrm{C} 1-\mathrm{C} 5$

difference between the polarities of the high and the low viscosity components should be changed to introduce a new component to control the difference. We have chosen esters, which have both hydrophobic and hydrophilic groups in the molecule as shown in Fig. 10, as the third component. A series of different kinds of esters those have different polarities and viscosities are commercially available and are proven components as lubricant [17]. This third component can dissolve into both high and low viscosity components, and the polarity of it should be between that of both components

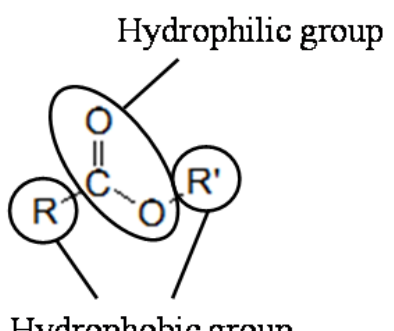

Hydrophobic group

Fig. 10 Structure of esters used for control elements of two phase lubricants

Table 11 Formulations, separation temperatures and viscosities of two phase lubricants

\begin{tabular}{cccccc}
\hline & \multicolumn{5}{c}{ Two phase lubricants } \\
\cline { 2 - 5 } & $\mathrm{C} 1$ & $\mathrm{C} 2$ & $\mathrm{C} 3$ & $\mathrm{C} 4$ & $\mathrm{C} 5$ \\
\hline Components & & & & & \\
Poly- $\alpha$-olefin / mass $\%$ & 90.0 & 75.0 & 50.0 & 25.0 & 10.0 \\
Polyalkylene glycol B / mass $\%$ & 10.0 & 25.0 & 50.0 & 75.0 & 90.0 \\
Separation temperature & & & & 25 \\
Kinematic viscosity at $100^{\circ} \mathrm{C} / \mathrm{mm}^{2} \mathrm{~s}^{-1}$ & 4.65 & 6.05 & 9.39 & 14.57 & 18.96 \\
\hline
\end{tabular}

\#) Measured by visual inspection 
Table 12 Formulations, separation temperatures and viscosities of two phase lubricants with control element

\begin{tabular}{lccc}
\hline & \multicolumn{3}{c}{ Two phase lubricants } \\
\cline { 2 - 3 } & D1 & D2 & D3 \\
\hline Components & 70.0 & 65.0 & 50.0 \\
Mineral oil A / mass\% & 20.0 & 20.0 & 20.0 \\
Polyalkylene glycol A / mass\% & 0.0 & 5.0 & 20.0 \\
Diisononyl adipate / mass\% & 10.0 & 10.0 & 10.0 \\
ATF additive package B / mass\% & & & 50.7 \\
& 68.5 & 57.5 & 18.5 \\
Separation temperature ${ }^{\#) ~} /{ }^{\circ} \mathrm{C}$ & 10.8 & 11.9 & 6.88 \\
Kinematic viscosity at $40^{\circ} \mathrm{C} / \mathrm{mm}^{2} \mathrm{~s}^{-1}$ & 6.30 & 6.48 & 389 \\
Kinematic viscosity at $100^{\circ} \mathrm{C} / \mathrm{mm}^{2} \mathrm{~s}^{-1}$ & 704 & 641 & \\
Apparent viscosity index & & & \\
\hline
\end{tabular}

\#) Measured by visual inspection

to control the separation temperature. It is expected that the difference between the polarities of the both components becomes smaller by addition of the third component into the two phase lubricants, and hence that the separation temperature of the lubricant becomes lower. The third component is called the control element in this paper, and the separation temperatures and the viscosity properties of the two phase lubricants were investigated.

The two phase lubricants with different ratio of the high and the low viscosity components and with different amounts of the control element were blended including ATF additive package B (Table 12), and the separation temperatures and the kinematic viscosities of them were measured. Their separation temperatures varied from $68.5^{\circ} \mathrm{C}$ to $50.7^{\circ} \mathrm{C}$ while the kinematic viscosities at $100^{\circ} \mathrm{C}$ of them were targeted around 6.5 $\mathrm{mm}^{2} \mathrm{~s}^{-1}$ and the viscosity indexes showed high values (Table 12). These results indicate that the viscosity and the separation temperature can now be simultaneously controlled and that the two phase lubricants can be formulated without limitation in the useful operating envelope shown in Fig. 11 (area between the black and the red lines).

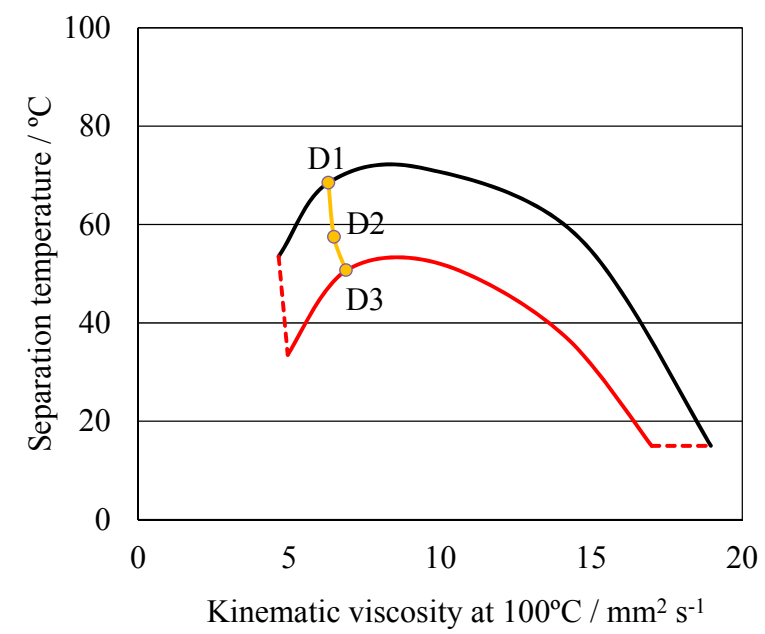

Fig. 11 Viscosity and separation temperature of two phase lubricants with control element

\section{Conclusions}

In this paper, we have investigated the practical applications of two phase lubricant technology with additional ability to control viscosity and separation temperature, and found the following conclusions.

1) Two phase lubricant has a super high viscosity index of more than 500 and has significant improvement potential for fuel efficiency. Trade-off properties, such as flash point and shear stability, of high viscosity index are competitive with commercial fluids. There is little evidence of issues with the lubrication properties, indicating that the two phase lubricant has a strong potential as a fuel economy lubricant.

2) A challenge for two phase lubricants was that if the kinematic viscosity is fixed, the separation temperature is uncontrollable making the practical use of the technology very difficult. By adding the control element, it is possible to control viscosity and separation temperature of the two lubricant phases simultaneously.

This novel technology has enabled the practical use of the two phase lubricant technology, and can be applied to improve the viscosity index of high performance lubricants. High flash Point, good shear stability, lubrication properties are competitive with the current commercially available fluids.

\section{References}

[1] Holmberg, K., Andersson, P. and Erdemir, A., "Global Energy Consumption due to Friction in Passenger Cars," Tribology International, 47, 2012, 221-234.

[2] Holmberg, K., Andersson, P., Nylund, N-O., Mäkelä, K. and Erdemir, A., "Global Energy Consumption due to Friction in Trucks and Buses," Tribology International, 78, 2014, 94-114. 
[3] Umamori, N. and Kugimiya, T., "Study of Viscosity Index Improver for Fuel Economy ATF," SAE Technical Paper, 2003-01-3256, 2003.

[4] Ushioda, N., Miller, T. W., Sims, C. B., Parsons, G. and Sztenderowicz, M., "Effect of Low Viscosity Passenger Car Motor Oils on Fuel Economy Engine Tests," SAE Technical Paper, 2013-01-2606, 2013.

[5] Fukumizu, T., Yamashita, M., Ogawa, M., Nishinosono, J., Sato, T. and Ishibashi, S., "Development of Continuously Variable Transmission Fluid for Fuel Economy," SAE Technical Paper, 2013-01-2584, 2013.

[6] Stoehr, T., Eisenberg, B. and Mueller, M., “A New Generation of High Performance Viscosity Modifiers Based on Comb Polymers," SAE International Journal of Fuels and Lubricants, 1, 1, 2009, 1511-1516.

[7] Jackson, A. and Peterson, B. K., "Multi-Phase Lubricant," US Patent 5602085, 1997.

[8] Kamata, K., Tazaki, H., Kawamura, Y. and Nagatomi, E., "The Viscosity Properties and the Evaluations for the Practical Use of the Two Phase Lubricant Which Possess High Viscosity Index (> 500)," Proc. JAST Tribology Conference, Fukuoka, October 2013, 201310A33 (in Japanese).

[9] Kamata, K., Tazaki, H., Kawamura, Y. and Nagatomi E., "The Development to Control Simultaneously Both Viscosity and Separation
Temperature of the Two Phase Lubricant for the Practical Use," Proc. JAST Tribology Conference, Fukuoka, October 2013, 201310A34 (in Japanese).

[10] Nagatomi, E., Kamata, K., Tazaki, H., Maruyama, R. and Kawamura, Y., "The Development to Control Simultaneously Both Viscosity and Separation Temperature of a Two Phase Lubricant for Practical Use," Proc. The $5^{\text {th }}$ Advanced Forum on Tribology 2014, Fuji, April 2014, 11.

[11] Kamata, K., Maruyama, R., Shinoda, N. and Tazaki, H., "Two-Phase Lubricating Oil Composition," US Patent 0194332, 2014.

[12] ASTM D611-12

[13] JIS Z8803:2011

[14] Nakano, K. and Spikes, H. A., "Process of Boundary Film Formation from Fatty Acid Solution," Tribology Online 7, 1, 2012, 1-7.

[15] Skurka, J. C., "Elastohydrodynamic Lubrication of Roller Bearings," ASME Journal of Tribology, 92, 2, 1970, 281-288.

[16] Jao, T. C., Devlin, M. T., Baren, R. E., Milner, J., Koglin, C., Ryan, H. and Hoeprich, M. R., "Prediction of Lubricant's Fatigue Life in the FZG Micropitting Test," SAE Technical Paper 2005-01-2179, 2005.

[17] Schlosberg, R. H., Chu, J. W., Knudsen, G. A., Suciu, E. N. and Aldrich, H. S., "High Stability Esters for Synthetic Lubricant Applications," Lubrication Engineering, 57, 2, 2001, 21-26. 